\title{
APLICAÇÃO DO COMPLIANCE NAS EMPRESAS DE MINERAÇÃO COMO MEDIDA PREVENTIVA DE DANOS AMBIENTAIS
}

\author{
Camila Cardoso Lima ${ }^{1}$ \\ Simone Cristina Izaias da Cunha ${ }^{2}$
}

Resumo: A implementação de Compliance ambiental na indústria mineradora é medida eficaz no cumprimento das leis e na prevenção de danos ambientais como os ocorridos em Mariana e Brumadinho? Para responder a problemática, foi realizada pesquisa bibliográfica e documental na doutrina e legislação ambiental. Por meio do método hipotético-dedutivo, buscou-se confirmar a hipótese inicial. Diante dos acontecimentos dos últimos anos, torna-se inadiável tal debate. Concluiu-se que as empresas ignoram a legislação, que o Poder Público é ineficiente na fiscalização e aplicação de sanções efetivas, sendo o Compliance ferramenta apta a evitar danos ambientais, pois compromete as organizações à legislação, conscientiza os envolvidos e proporciona ações preventivas e medidas para a mitigação dos impactos.

Palavras-chave: Compliance; Atividades de Mineração; Prevenção; Rompimento de Barragens; Dano Ambiental.

Abstract: Is the implementation of Environmental Compliance in the mining industry an effective measure for complying with laws and preventing environmental damage such as occurred in Mariana and Brumadinho (MG, Brazil)? To answer the problem, bibliographic and documentary research on environmental doctrine and legislation was carried out. Through the hypothetical-deductive method, we tried to confirm the initial hypothesis. In view of the events of the last few years, such a debate becomes urgent. It was concluded that the companies ignore the legislation, that the Public Power is inefficient in the inspection and application of effective sanctions, being the Compliance tool able to avoid environmental damages, because it compromises the organizations to the legislation, makes the involved involved aware and provides preventive actions and measures for mitigating impacts.

Keywords: Compliance; Mining activities; Prevention; Breaking of Dams; Environmental Damage.

\footnotetext{
1 Universidade Pitágoras Unopar, Londrina-PR. E-mail: cclima.cl@gmail.com.

2 Universidade Pitágoras Unopar, Londrina-PR. E-mail: ssimone.izaias@gmail.com.
}

Revista brasileira educação ambiental 


\section{Introdução}

O presente trabalho tem por objetivo analisar os impactos e consequências da atividade mineradora, concentrando-se na aplicação do Compliance como forma de garantir o cumprimento das normas que regulamentam a atividade e medida preventiva efetiva na ocorrência de danos ambientais como os experenciados nas cidades de Mariana e, mais recentemente, em Brumadinho.

Diariamente nos jornais nos deparamos com o noticiário dando destaque ao tema corrupção, desvio de recursos públicos, caixa dois, quebra de grandes empresas, pagamentos de propinas entre outros escândalos. Tem se tornado, quase uma regra em nosso país, a preocupação tardia dos órgãos do Poder Público em tapar as lacunas e corrigir erros de fiscalização e monitoramento após a ocorrência de eventos trágicos, como os rompimentos das Barragens nas cidades de Mariana e Brumadinho, ambas no Estado de Minas Gerais.

Contudo, a preocupação em fiscalizar e fazer valer as regras e leis ambientais de maneira efetiva e em real cumprimento ao princípio da prevenção deveria permear e até mesmo nortear as ações dos órgãos responsáveis.

A proteção ambiental, a conservação dos recursos naturais para as presentes e futuras gerações, a manutenção do equilíbrio ecológico indispensável a todas as formas de vida são o grande desafio da contemporaneidade. A sociedade atual passa exigir uma mudança de comportamento das empresas no que consiste a responsabilidade ambiental. As questões ambientais na sociedade contemporânea exigem um novo paradigma ético para todos e especial para as empresas, vez que a lógica de atendimento tão somente ao aspecto econômico, não é mais suficiente para manutenção, promoção e desenvolvimento dela.

A expressão sustentabilidade passou a permear as atividades empresariais nos mais diversos segmentos de atuação, trazendo a ideia de que as mesmas devem se apoiar nos clássicos pilares da sustentabilidade, quais sejam: eficiência econômica, responsabilidade social e preservação ambiental. No entanto, essa nova postura empresarial depende da implementação de uma "cultura" ambiental nas empresas, para que a preocupação com o ambiente esteja presente em todas as etapas do processo produtivo e possam se concretizar, prevenindo com eficiência a ocorrência de danos à natureza.

Dessa forma, surge a ideia do Compliance que, embora esteja muito relacionado ao cumprimento normativo, possuí indubitável caráter pedagógico, pois sua implantação nas empresas depende de uma sensibilização e adesão de todos os colaboradores, fornecedores e todos os stakeholders.

Sucintamente, Compliance significa, o conjunto de medidas à serem adotadas por agentes econômicos, nos mais diversos seguimentos, para prevenir e minimizar riscos no que tange ao descumprimento de leis, sejam 
elas de cunho econômico, concorrencial ou ambiental, esse último, objeto de análise do presente trabalho.

No entanto, é possível identificar que o objetivo perseguido pelas empresas com a incorporação do Compliance é um grande desafio, que exige a implantação de uma nova cultura organizacional, vez que o programa somente alcançará resultados positivos se a organização for capaz de envolver os colaboradores de maneira sistêmica.

A implementação de programas de Compliance na seara ambiental nas atividades econômicas são, não só uma exigência da sociedade, mas também uma exigência legal, funcionando como medida preventiva na ocorrência de danos como os destacados nesse texto.

Nesse sentido, pretendeu-se ao longo desse estudo demonstrar a importância e a viabilidade da utilização de programas de Compliance ambiental.

\section{Mariana e Brumadinho: breve relato dos fatos e medidas adotadas}

O rompimento da barragem de Fundão da empresa Samarco Mineração S.A, controlada pelas empresas VALE e BHP Billiton no ano de 2015, deixou consequências ao meio ambiente e ao ecossistema que até hoje não foram reparas, e talvez nunca serão. $O$ trágico acidente despejou ao meio ambiente certa de 62 milhões de metros cúbicos de rejeitos advindos da prática da mineração, onde a formação principal é por óxido de ferro, lama e água. Muito embora os organismos encontrados nos rios foram afetados e a grande parte mortos, não é este apenas o impacto ambiental causado pelo rompimento da barragem, existe também a situação de que muitos rios irão sumir, sofreram assoreamento, mudança de curso, soterramento e a profundidade iria diminuir.

A cobertura de lama afetou um afluente do rio Carmo o rio Gualaxo esse rio deságua em um outro Rio muito importante para o estado de Minas Gerais o Rio Doce chegando ao mar, onde biólogos temem que no Estado do Espírito Santo os rejeitos afetem os recifes de corais um local onde há muitas espécies de vidas marinhas.

Após a tragédia no município de Mariana, quase nenhuma medida foi adotada pelo Poder Público a fim de minimizar os prejuízos ambientais ou melhorar as medidas de prevenção em outras barragens da mesma espécie. De acordo com o superintendente do IBAMA em Minas Gerais, Julio Cesar Dutra Grillo, em entrevista concedida para BBC News Brasil, em 26/01/2019, "há mais de 300 barragens de rejeitos em Minas Gerais que não seguras". Contudo, mesmo diante do risco premente, as barragens de rejeitos provenientes da mineração não são devidamente fiscalizadas e não há, por parte das empresas, qualquer interesse em investir em práticas de segurança efetivas.

O fato ocorrido no município de Brumadinho/MG, era uma tragédia anunciada, após o ocorrido foram identificas inúmeras irregularidades, todavia

Revista brasileira educação ambiental 
observa-se que a empresa está preocupa em obter lucros e não perder dinheiro. Considerando o apurado e noticiado pelos mais diversos veículos de comunicação, é notório que a empresa deixou de investir dinheiro em custos operacionais, este ligados a manutenção e segurança, a empresa Vale demonstrou uma atitude empresarial antiética em relação a sua atuação no mercado de exploração de minérios.

E empresa obteve a licença para operação da barragem de forma muita rápida, onde deixa pontos escuros no qual as pessoas passam a dúvidas da atuação de fiscalização e análise de documentos para liberação das licenças de exploração, este licenciamento ocorreu na década de 1970, no ano de 2016 a barragem foi desativada, e suas atividades paralisadas, não obstante no ano de 2018 a Vale obteve a autorização para que trabalhassem na descaracterização da barragem (BOSCO, 2017)

No dia 25 de janeiro de 2019 a barragem de rejeitos da mina Córrego do Feijão rompeu-se deixando centenas de pessoas mortas e outras centenas desaparecidas, causando um enorme desastre ambiental com danos irreparáveis, um verdadeiro "mar de lamas". Sofrendo uma pressão grande do governo e da população, a mineradora afirma não haver riscos iminentes de novos rompimentos, embora, nos meses que se seguiram, novos alertas soaram em outras cidades do Estado de Minas.

A onda de rejeitos que passou por Brumadinho, deixou consequências devastadoras, tanto para o ser humano como para o meio ambiente. Os impactos deixados pela lama são de grade extensão social (vidas, casa e propriedades rurais, de onde as pessoas tiravam seu sustento) e toda a poluição deixada no solo e na água, levando a contaminação dos mesmos por metais pesados, mortandade de peixes e outros animais e destruição da flora local.

As primeiras investigações realizadas após a tragédia, apontam para evidências de que a direção da empresa detinha informações que anunciavam o rompimento, mas nada fez. Após o desastre, a mineradora se pronunciou dizendo que tomaria algumas atitudes para compensar o meio ambiente e as pessoas diretamente atingidas no desastre, contudo, até o presente momento, nenhuma medida significativa foi adotada e uma grande indignação toma conta da comunidade em geral, que mais uma vez presencia a impunidade de uma grande empresa exploradora minério de ferro (MOTA, 2017).

Estima ser impossível aferir a dimensão do impacto ambiental que ocorreu neste crime, houve uma grande quantidade de vazamento de rejeitos que atingiu grande parte da vegetação, rios e animais, entretanto somente após um minucioso estudo será possível mensurar, com maior precisão, todos os danos. Por isso defende-se ser necessário que órgãos competentes por liberar as licenças sejam mais rígidos, e que estes executem uma fiscalização mais ativa em relação a atuação das mineradoras. 
O Ministério Público após investigações feitas, até o momento afirma que o que ocorreu em Brumadinho não foi um acidente, pois a barragem vinha apresentando sinais de ruptura. Uma empresa que prestava consultoria para Vale apresentou documentos que relatavam o baixo índice de segurança, segundo a investigação em vez de tomar providências para evitar a ruptura a Vale optou pelo método mais barato, as normas técnicas não foram cumpridas de acordo com a licença ambiental (LOPES, 2016).

Importante numerar que são vários os impactos ambientais causados nos casos de rompimento de barragens de rejeitos de minério, como em Mariana e Brumadinho, destacando-se algumas:

- Com o mar de lamas há a remoção de toda a vegetação da área afetada;

- Recursos hídricos são prejudicados devido a derramamento de produtos químicos contaminantes;

- O solo é contaminado por diversos elementos tóxicos;

- Os animais precisaram de forma forçada se evadirem do local e muitos morrem;

- Poluição de rios e mar pela contaminação da lama contendo componentes que prejudicam a qualidade dessas águas e da vida animal e vegetal ali presentes.

A avalanche de rejeitos que atingiu as cidades de Mariana e mais recentemente, Brumadinho, causou danos ambientais e sociais imensuráveis. Comunidades inteiras foram atingidas, abastecimento de água foi suspenso em diversos pontos, centenas de pessoas morreram. Ambientalistas afirmam que 0 desastre em ambas as situações já era esperado em virtude da atuação negligente das empresas controladoras e normas que foram ignoradas por falta de fiscalizações pelos órgãos governamentais responsáveis.

Existem falhas no modelo de mineração, a falta de efetivo dos órgãos responsáveis inviabiliza a atuação para que as regras se cumpram, deixando evidente que o controle da atividade de mineração no Brasil relega a segurança à fator secundário, priorizando a obtenção de lucros em detrimento da proteção do meio ambiente e da população.

Dessa forma, considera-se estarmos diante de uma política de prevenção omissa, onde as punições por crimes ambientais não induzem as empresas a promoverem mudanças. 


\section{Legislação ambiental brasileira e o uso do Compliance Ambiental como medida de prevenção de danos}

No Brasil a gestão ambiental é normatizada pela Política Nacional do Meio Ambiente Lei 9.69838/1981 - PNMA. Pode-se dizer que o Brasil possui umas das leis ambientais mais avançadas e mais completas do mundo, elaborada a fim de tutelar o meio ambiente de maneira sistêmica e restringir as possibilidades de degradação ambientais provenientes de atividades potencialmente poluidoras.

Por ser considerada atividade de grande potencial de dano para o meio ambiente, a atividade mineradora está sujeita à licenciamento ambiental, que deverá estabelecer entre as condicionantes, ações de contingência para situações de emergência e também medidas mitigadoras de dano, ou seja, medidas preventivas, vez que, em se tratando de ambiente natural, a recomposição ao status quo ante em uma situação como a havida em Mariana e Brumadinho, é quase impossível.

A sociedade civil organizada, incluindo-se aqui os agentes econômicos, tem papel fundamental na construção do desenvolvimento sustentável, podendo ser a grande disseminadora da sustentabilidade no âmbito local, orientando a sustentabilidade no aspecto global. Vale dizer, conta-se com um agir local, mas com pensamento global (REIS; FADIGAS; CARVALHO, 2005).

Disso decorre o dever das empresas, não meramente por imposição legal, mas derivado de uma responsabilidade social de adotar instrumentos econômicos e sociais aptos a reparar ou minimizar de alguma forma o mal causado por suas atividades.

É assim que surge um novo paradigma de produção baseado no potencial ecológico do território envolto a empresa e na promoção da sustentabilidade através de bases ecológicas e culturais, mediante a diferenciação entre crescimento econômico e desenvolvimento e mobilização da sociedade para engajar-se na defesa do patrimônio natural (LEFF, 2008).

É com base nessa necessidade premente de agir antecipadamente aos danos ambientais e catástrofes coletivas, que se propõe o Compliance ambiental, como alternativa viável e efetiva.

Alguns administradores e gestores ignoram a importância dos controles internos, pois acreditam que estes não possuem grande relevância. Acreditam que a gestão de risco associada à gestão de Compliance não passa de um modismo, entretanto, no mundo coorporativo atual, impossível gerir uma organização de sucesso sem aplicação destas duas gestões, sendo este, um caminho sem volta.

O Compliance, vem do verbo inglês "to comply with" e sua tradução representa: observância, conformidade submissão ou complacência (CUNHA; SOUZA, 2017), quer dizer estar em conformidade com as leis, padrões éticos, regulamentos internos e externos, ou seja, cumprir a lei. No entanto, como 
destacado por Veríssimo (2017, p.91) o termo Compliance não significa somente o cumprimento das normas legais, está também associado ao comportamento da atividade empresarial diante da sociedade.

Podemos entender o Compliance com uma linha que irá guiar o comportamento da empresa diante do mercado em que atua, com o propósito de minimizar os riscos que ela poderá encontrar em sua caminhada.

No Brasil o Compliance passou a ganhar forças após a promulgação da Lei $\mathrm{n}^{\circ}$ 12.846/13, Lei Anticorrupção e cm sua regulamentação pelo Decreto $\mathrm{n}^{\circ}$ 8.420/15.

A primeira medida para a implantação do Compliance em uma empresa seria a elaboração de Código de Condutas, ou seja, como uma empresa introduz essa gestão em sua rotina. Este Código precisa ter uma linguagem acessível, capaz de sensibilizar e realizar a conscientização dos funcionários, de modo que, passem a entender a importância de seguir os padrões e incorporar as práticas adotadas pela empresa.

Nesse sentido, observa-se aspectos do Compliance trazida pelos autores Mendes e Carvalho (2017. p.31)

Um programa de compliance visa estabelecer mecanismos e procedimentos que tornem o cumprimento da legislação parte da cultura corporativa. Ele não pretende, no entanto, eliminar completamente a chance de ocorrência de um ilícito, mas sim minimizar as possibilidades de que ele ocorra, e criar ferramentas para que a empresa rapidamente identifique sua ocorrência e lide da forma mais adequada possível com o problema.

Necessário ainda, que haja canais internos onde os funcionários possam fazer denúncias, nas quais serão relatadas atividades que estejam em desconformidade com as regras estabelecidas pela empresa.

Ao final a empresa precisa fazer o monitoramento dos programas de Compliance, podendo ser através de revisão periódica, treinamento e ações específicas focando em riscos jurídicos e socioambientais.

Tamanho o êxito obtido pelo Compliance no âmbito financeiro, que estimulou sua prática em outros campos de ação. Nesse sentido, conforme destacado por Cunha e Souza (2017, p. 76):

Compliance pode ser definido então como conjunto de ações e planos adotados facultativamente por pessoas jurídicas visando garantir que cumpram todas as exigências legais e regulamentares do setor ou segmento econômico em que atuam, inclusive preceitos éticos e de boa governança administrativa. 
Como já mencionado anteriormente, contudo, o Compliance Ambiental nas empresas tem o papel prolífico de disseminar uma verdadeira "cultura" ecológica nas empresas onde se promovem, tendo inegável caráter educativo, não só para a empresa, mas todos os envolvidos.

Quanto à educação ambiental empresarial, Pedrini (2008) leciona que as empresas devem perceber os programas de educação ambiental como uma oportunidade de ganho, tanto para si próprias como para a sociedade devendo tratá-la como instrumento estratégico com estabelecimento de objetivos no sentido de incorporar a visão holística e crítica da problemática ambiental entre os seus colaboradores.

No que tange à tutela do meio ambiente, esta preocupação deve ser estendida a todos, não somente aos empresários, envolvendo todos os setores que participem da atividade econômica. Nesta esteira, diante de inúmeras normas que regulamentam a esfera ambiental, vê-se necessário a pessoa jurídica se antecipe, buscando através prevenção, evitar de sanções jurídicas.

Grandes empresas estão trabalhando de forma consciente, entendem a importância da preservação ambiental para um futuro sustentável, empenhando-se para trabalhar de acordo com a legislação ambiental, destacando-se no mercado. Ademais, estas empresas elevam seu conceito junto ao mercado, tornando-se mais valorizadas, pois aumentam seus números em decorrência de ações sustentáveis, por meio do Compliance, evitam demandas judiciais e ganham credibilidade no mercado.

É possível perceber que pela aplicação do Compliance, as pessoas de fora da empresa, assim como seus colaboradores passam a ter uma imagem sólida da empresa, comprometendo-se em buscar elucidações para os problemas antes que ocorram, conquistando uma melhor aceitação no mercado.

A aplicação do Compliance dentro das exigências da lei ambiental, irá identificar pontos suscetíveis a falhas, vindo de encontro com a preservação do meio ambiente, por meio da identificação dos riscos potenciais envolvidos no processo de produção, tomando as medidas de prevenção para evitar situações como as ilustradas nessa pesquisa. Observa-se que o programa de Compliance aplicado dentro das instituições como ferramenta de educação permite que as empresas tenham em seus planos uma eficácia no cumprimento de seus requisitos regulatórios, visando assegurar que os critérios deste cenário sejam resguardados com integridade.

Nesse sentido o programa de Compliance com viés educacional aplicado aos funcionários das empresas irá servir como instrumento utilizado para tomada de decisão por parte dos empresários, aspirando melhor desempenho das mineradoras, identificando oportunidade de ganhos e a redução dos riscos ao meio ambiente e ao ser humano. Dessa forma o programa de Compliance com enfoque educacional dentro das empresas, certamente ganhará cada vez mais adeptos da técnica. 


\section{Conclusões}

Por conseguinte, percebe-se a relevância do cumprimento das leis ambientais pelas empresas, em especial, as empresas de mineração, que nos últimos anos têm sido responsáveis por grandes danos ao meio ambiente, como os decorrentes dos rompimentos de barragens de Mariana e Brumadinho, sem adentrar no mérito de outras que no Estado de Minas Gerais que encontram-se sob alerta.

O Brasil possui inúmeras leis de proteção ambiental, tendo como foco principal a prevenção a eventos como os mencionados nessa pesquisa. Danos ao meio ambiente e à população, irreparáveis e de grande extensão e gravidade, entretanto, o que se percebe na prática é o descaso por parte das empresas e uma ineficiência por parte do Poder Público, vez que os órgãos responsáveis pelo licenciamento e fiscalização das atividades encontra-se sem sobrecarregados e desprovidos de recursos mínimos para desempenhar suas funções de forma eficaz.

Nesse sentido, a aplicação de programas de Compliance ambiental se tornam de significativa relevância, já que por meio do Compliance as empresas se comprometem com o cumprimento das leis ambientais, promovendo a conscientização e sensibilização de todos os envolvidos nos processos produtivos, culminando a criação e fortalecimento de uma "cultura" de proteção, colaborando de maneira significativa e efetiva na preservação do meio ambiente. As empresas também se beneficiam com a implementação do Compliance ambiental, pois adquirem boa reputação no mercado, a "simpatia" dos consumidores e credibilidade junto a fornecedores e financiadores.

Infelizmente, no Brasil as medidas preventivas são negligenciadas e "remediar" acaba sendo, quase sempre, a primeira opção. A postura empresarial sem compromisso com o ambiente ou com a população é inaceitável e exige das autoridades públicas, medidas de responsabilização enérgicas contra os poluidores. Exatamente nesse aspecto que o Compliance se mostra como alternativa eficiente e interessante para todos os envolvidos.

Um programa de Compliance sério poderia ter sido determinante em Mariana e Brumadinho, evitando o rompimento das barragens com a adoção de ações preventivas e/ou minimizados os impactos sociais e ambientais por meio de medidas mitigadoras e cumprimento de condicionantes.

O Compliance no Brasil ainda caminha a passos lentos, tendo como principais obstáculos o argumento do custo e o comodismo que a ineficiência de fiscalização e responsabilização fazem crescer. Se não houver fiscalização rigorosa no cumprimento das leis ambientais e consequências expressivas para os danos ambientais causados, fica a impressão, que poluir compensa.

Os programas de Compliance são importantes para desfazer esse pensamento, alterando a postura organizacional, mas também conscientizando da sociedade para torná-la mais exigente em relação as empresas, para na ausência de estrutura do Poder Público (em nosso pais, uma realidade), a

Revista brasileira educação ambiental 
própria sociedade possa atuar na fiscalização desses empreendimentos, impedindo que novos crimes ambientais, como os ocorridos em Mariana e Brumadinho devastem o meio ambiente e prejudiquem a população.

\section{Referências}

BOSCO, J. Todos desejamos o minério de Brumadinho. Disponível em: $<$ https://epoca.globo.com/>. Acessado em: 08 mar.2019.

BORGES, A.C. O Licenciamento ambiental e seu aspecto jurídico. Disponível em: <www.ambitojuridico.com.br>. Acessado em: 08 mar.2019.

CUNHA, R.S.; SOUZA, R. Lei Anticorrupção Empresarial. Salvador: Juspodivm, 2017.

FARIAS, T. Licenciamento Ambiental: Aspectos Teóricos e Práticos. 1. ed. Belo Horizonte: Fórum, 2007.

FREIRE, W. Direito ambiental aplicado à Mineração. Belo Horizonte: Editora Mineira de Livros Jurídicos, 2005.

FIORILLO, C.A.P. Curso de Direito Ambiental Brasileiro. 9 ed. São Paulo: Saraiva, 2008.

JARDIM, W.F. O desastre de Mariana é o retrato do Brasil. Disponível em: <http://www.unicamp.br/unicamp/noticias/2015/11/23/artigo-o-desastre-demariana-e-o-retrato-do-brasil>. Acesso em: 02 de abril de 2019.

LEFF, E. Saber Ambiental: sustentabilidade, racionalidade, complexidade, poder. Tradução de Lúcia Mathilde Endlich Orth. Rio de Janeiro: Vozes, 2008.

LOPES, R.A.L. Caso do desastre socioambiental da Samarco. In.: MILANEZ; LOSEKANN. Desastre no vale do Rio Doce. Rio de Janeiro: Editora Folio Digital, 2016, p. 373-392.

MENDES, F.S.; CARVALHO, V.M. Compliance: concorrência e combate à corrupção. São Paulo: Trevisan, 2017.

MEIRELLES, H.L. Direito Administrativo Brasileiro. 24 ed. São Paulo: Malheiros, 1999.

MILARÉ, E. Direito do ambiente. 8 ed. São Paulo: Revista dos Tribunais, 2013.

MINISTÉRIO DO MEIO AMBIENTE (MMA). Disponível em: <www.mma.gov.br>. Acessado em: 10 março.2019

MOTA, C.V. A pós dois anos, impacto ambiental do desastre em Mariana não é totalmente conhecido. Disponível em: $<$ https://www.bbc.com/portuguese/brasil>. Acessado em: 20 mar.2019.

PEDRINI, A.G. (org.). Educação ambiental no Brasil. São Carlos: RiMa Editora, 2008. 
REIS, L.B.; FADIGAS, E.A.A; CARVALHO, C.E. Energia, recursos naturais e a prática do desenvolvimento sustentável. São Paulo: Manole, 2005.

VERÍSSIMO, C. Anticorrupção e Compliance: A incapacidade da lei 12.846/2013 para motivar as empresas brasileiras à adoção de programas e medidas de compliance. 2016. $339 \mathrm{f}$. Tese (Doutorado) - Curso de Direito, Universidade Federal do Rio Grande do Sul, Porto Alegre, 2016. Disponível em: < http://hdl.handle.net/10183/149239 >. Acesso em: 12 de março 2019.

VERÍSSIMO, C. Compliance: incentivo à adoção de medidas anticorrupção. São Paulo: Saraiva, 2017. 